\title{
$\mathrm{C}|\mathrm{E}| \mathrm{D}|\mathrm{L}| \mathrm{A} \mid \mathrm{S}$
}

Centro de Estudios

Distributivos, Laborales y Sociales

Maestría en Economía

Facultad de Ciencias Económicas

Universidad Nacional de la Plata

\section{Youth Training Programs Beyond Employment. Experimental Evidence from Argentina}

María Laura Alzúa, Guillermo Cruces y Carolina Lopez

Documento de Trabajo Nro. 177

Enero, 2015

ISSN 1853-0168 


\title{
Youth training programs beyond employment. Experimental evidence from Argentina*
}

\author{
María Laura Alzúa \\ CEDLAS-FCE-UNLP, \\ and CONICET
}

\author{
Guillermo Cruces \\ CEDLAS-FCE-UNLP, \\ CONICET and IZA
}

\author{
Carolina Lopez \\ CEDLAS-FCE-UNLP, \\ and CONICET
}

September 2014

\begin{abstract}
Youth training programs and their evaluations are ubiquitous, yet there is relatively little evidence on the mechanisms through which they operate and their effect on outcomes beyond the labor market. This is the motivation of our study of entra21, a job training program for low income youth in Cordoba, Argentina. The program included life-skills and vocational training, as well as internships with private sector employers. Participants were allocated by means of a public lottery. We rely on detailed monthly administrative records for program participants, from which we construct a panel dataset including formal employment status, employment spells, earnings and welfare participation. These administrative records allow us to establish the effects of the program in the short term (18 months), but also - exceptionally for programs of this type in Latin America - in the medium term (36 months). The results indicate sizable gains of about 8 percentage points in formal employment in the short term (about 32\% higher than the control group), although these effects tend to dissipate in the medium term. Contrary to what has been found for similar programs in the region, the effects of entra21 are substantially stronger for men, for whom the effects persist in the medium run. A dynamic analysis of employment transitions indicates that the program operates through an increase in the persistence of formal employment rather than from more frequent entries into employment. Program participants also exhibit earnings up to $50 \%$ higher than those in the control group, and an analysis of bounds indicates that these gains result from both higher employment levels and higher wages. The higher persistence and higher earnings suggest that the program was successful in increasing the human capital of participants rather than (or in addition to) providing contacts or formal intermediation. With respect to results beyond employment, women selected for the program exhibit lower levels of welfare dependency younger participants (aged 18 to 24) are less likely to receive child-related public cash transfers over the whole period of analysis. Finally, we present original evidence on the relationship between formal employment and consumer credit use. Program participants exhibit a higher probability of having requested consumer credit, and a higher probability of holding bank debts in good standing. These results indicate that training and internship programs directed at disadvantaged youth can provide other indirect benefits that are not usually accounted for in existing evaluations.
\end{abstract}

JEL Classification: J08, J24, J68, O15.

Keywords: youth labor training programs, youth unemployment, field experiment.

${ }^{*}$ Centro de Estudios Distributivos, Laborales y Sociales, Facultad de Ciencias Económicas, Universidad Nacional de La Plata (CEDLASFCE-UNLP), Calle $6 N^{\circ} 777$, La Plata, Buenos Aires, Argentina; Consejo Nacional de Investigaciones Científicas y Técnicas (CONICET); and Institute for the Study of Labor (IZA). We would like to thank Marcelo Bergolo, Xuan Cheng, Carlos Flores, Leonardo Gasparini, Marco Manacorda, Oscar Mitnik, Ricardo Perez-Truglia, Elena Heredero Rodríguez and Yuri Soares for their comments, as well as seminar participants at Universidad de San Andrés, Université de Neuchatel MIF-IDB, AAEP (Universidad Nacional de Rosario, 2013), LACEA Labor Network Conference (Univesity of Maryland, 2013), IZA/SOLE Trasatlantic Meeting of Labor Economist (Buch/Ammersee, Germany, 2013) and IZA Labor and Development Conference (Universidad del Pacífico, Lima, 2014). We would also like to thank Julián Amendolaggine, Nicolás Badaracco and Paula Corti for excellent research assistance. We also thank Susan Pezzulo at the International Youth Foundation, which provided and acknowledge financial support for the evaluation, as well as help with logistics and data gathering from Marta Novick, Diego Schleser and Lucía Tumini (Ministerio de Trabajo, Empleo y Seguridad Social de la Nación), and Félix Mitnik, Luciano Donadi and Leandra Bernard (Agencia para el Desarrollo de Córdoba).

Corresponding author: gcruces@cedlas.org 


\section{Introduction}

Youth unemployment is a pervasive phenomenon in Latin American. Unemployment among youth is three times greater than for adults, labor informality is the norm (Gasparini et al., 2011), and, with little work experience, young people find insertion into the labor market difficult (e.g. Pallais, 2014). Governments and aid agencies have explored training programs as a potential solution to this problem in developing countries, following the extensive experience of active labor market policies carried out in more advanced economies. Policy interventions have centered on at-risk youth, including low income youth who have not completed their education, are poor or have experienced poverty, and are either unemployed or working under precarious conditions (see Vezza, 2014, for an overview of these initiatives in Latin America). Despite the ubiquity of these programs and a longstanding literature on their evaluation, there is relatively limited evidence on the mechanisms through which they operate in developing countries, and on their effect on outcomes beyond the labor market. This is the motivation of our study of entra21, a job training program for low income youth in Cordoba, Argentina. We present evidence on the programs' effect on employment and earnings, and on other less studied outcomes that could be potentially affected by programs of this type, such as welfare dependency and access to consumer credit.Moreover, the use of detailed monthly administrative data on employment and earnings collected over a relatively long period of time allows us to disentangle the mechanisms through which the program operates, for instance whether the positive employment effects of the program can be attributed to labor market intermediation or if they reflect real gains in participants' human capital.

In a meta-study of active labor market program, Card et al. (2010) indicate that training programs in Europe and the United States have, at best, a moderate impact, and that they are generally most effective for women and for older workers. Moreover, firm-based training often exhibits better results than classroom training, and programs with work experience in the private sector tend to be more effective than public sector-based programs. In terms of methodology, there is a substantial literature on the evaluation of training programs by means of randomized controlled trials, covering initiatives such as the National Supported Work (NSW) and the Job Training Partnership Act (JTPA) in the United States. González-Velosa et al. (2012) review the available evidence for Latin America, and they highlight the fact that most programs in the region are not evaluated, and when they are, the resulting studies often consist of quasiexperimental evaluations. However, there is a growing literature that has provided experimental evidence regarding the effectiveness of these programs in Latin America and other developing countries.

Attanasio et al. (2011) present the results form an experimental evaluation of Colombia's youth training program, Jóvenes en Acción, implemented in 2005. This program targeted unemployed youth (aged between 18 and 25) from poor households. The program consisted of six months of vocational training. The evidence suggests that the program had positive effects on women's 
wages (an increase of 19.8\%). Moreover, women were also more likely to be employed, especially in formal employment, following participation. For men, program participation had little effect on employment levels, and quality of employment was not affected either. Card et al. (2011) and Ibarrarán et al. (2014) present the evaluation of several cohorts of Programa Juventud y Empleo, a youth training program in the Dominican Republic, by means of randomized controlled trials. This program targeted young people who had not completed high school and fell between the ages of 18 and 29. It aimed to increase the employability of vulnerable youth through technical/vocational courses and life-skills training. Results for the 2004 cohort (Card et al., 2011) indicate no significant impact on employment and a modest impact on wages conditional on having a job. Evidence obtained from other Programa Juventud y Empleo cohorts indicates that the program had small or null effects on overall employment, with small impacts on formal jobs and salaries for those employed (Ibarrarán et al., 2014). Our paper is also related to Hirshleifer et al.'s (2014) experimental study of a vocational training program for the unemployed in Turkey. As in our study, these authors use administrative data to follow beneficiaries for up to three years after the program. They find no effects of training on employment and only moderate effects on the quality of employment in the short run, but these effects dissipate after three years.

The program on which we focus, entra21, differs in some aspects from the programs listed above. It is a regional initiative carried out in different countries. Although governments can participate in its implementation, the program is based in the private sector and it is usually run by nongovernmental organizations (usually business associations). In addition to not being a national program, it is usually smaller and more costly than the government programs. The program's main objective is to improve the employment opportunities of at-risk youth by building their technical skills and life-skills through courses and work experience in the private sector. The program included a regionally standardized classroom-based life-skills training module, as well as vocational training and internships coordinated with private sector employers. The edition of the entra21 program that we study was administered by a pubic-private non-profit set up by professional and business associations and Cordoba's Municipality (Argentina), in close coordination with private sector employers. Our experimental impact evaluation is based on the first cohort of the program, for which participants were assigned to a treatment or a control group through a public lottery. We rely on detailed monthly administrative social security records for program participants, including formal employment status (the programs' main intended outcome), employment spells, earnings and welfare participation. While most evaluations of this type in Latin America cover only the short term impact of similar programs, these administrative records allow us to compare outcomes from up to eight years before the program, and to establish its effects in both the short term (18 months after the program) and in the medium term (36 months after the program). ${ }^{1}$

\footnotetext{
${ }^{1}$ Card et al.'s (2010) meta-review classifies the time frame of programs of this type as "short-term impact" (one year after the completion of the program), "medium-term estimate" (approximately 2 years after completion), and "longer-term (3 year) impacts". We refer to our effects after 18 months as short term, and after 36 months as
} 
The results indicate sizable gains of about 8 percentage points in formal employment with respect to the control group in the short term (about $32 \%$ higher), although these average effects tend to dissipate in the medium term. Program participants also exhibit substantially higher earnings (up to 50\% higher than those in the control group), and an analysis of bounds indicates that these gains result both from higher employment levels and from higher wages. Contrary to what has been found for similar programs in the region (e.g., Attanasio et al., 2011; Card et al., 2011; Ibarrarán et al., 2014), the effects of entra21 on employment and earnings are substantially stronger for men. Contrary to the average impact of the program, the effects for men persist in the medium run. In addition to these short and medium run results, we also exploit the detailed panel data structure of the administrative records to shed light on the mechanisms through which the program increases employment and earnings. A dynamic analysis of employment transitions indicates that the program operates mainly by increasing the persistence of formal employment (especially for men) rather than by fostering entries into formal employment. Beneficiaries also exhibit a higher probability of staying with the same employer over time.

Most of the existing literature on training programs examines the effects on employment and wage levels. While these are the programs' main intended outcomes, there are reasons to expect effects on other dimensions. It is plausible that training programs' effects on employment and earnings, in turn, reduce the use of welfare programs. We study entra21 female beneficiaries' participation in a large cash transfer program for families with children that targets unemployed and informal workers. Our findings show that women selected for the program exhibit lower levels of welfare dependency - younger participants (aged 18 to 24) are less likely to receive child-related public cash transfers over the whole period of analysis than those in the treatment group.

We also use the entra21 youth training program evaluation to study the relationship between formal employment and the use of consumer credit, prompted by the potential effect of increased formal employment and earnings. The existing literature has often concentrated in the opposite direction - how access to credit by means of specific government programs or micro-credit may foster self-employment and entrepreneurship (see for instance Premand et al., 2012, and Duflo et al., 2013). However, formal employment (which in Argentina defaults to open-ended contracts) provides a relatively stable stream of income, which is also easier to verify and to collateralize than most other income sources. Coelho et al. (2012) illustrate the latter effect in Brazil, where banks were allowed to offer loans with repayment through automatic payroll deduction, which resulted in a reduction in interest rates and higher volumes of consumer credit. Gutierrez (2014), in turn, shows that formal labor contracts in Mexico reduce wage fluctuations and serve as income smoothing mechanisms against productivity and other shocks. The programs' positive impact on formal employment could thus facilitate the use of consumer credit, which would imply that the effects of training go beyond those currently explored by the literature. Insofar as it helps to reduce risk, a central feature in the life of vulnerable groups, credit use constitutes a relevant medium term. 
outcome of programs like entra21. ${ }^{2}$ We matched individuals in the treatment and control groups to administrative records on consumer credit use from credit rating agencies and from the Central Bank's registry of consumer debt. Program participants exhibit a higher probability of having requested consumer credit, and a higher probability of holding bank debts in good standing. These effects, however, only appear in the short run for the whole sample, but they are stronger and persist in the medium run for male participants.

Training programs are designed to build human capital and foster the acquisition of skills, and their main expected outcome is improved employment. However, these programs can also facilitate the contact of beneficiaries with the labor market, providing work experience, implicit or explicit labor market intermediation, contacts and references for future employment. These effects could be present even if the programs fail to build or reinforce beneficiaries' skills and human capital. If the program increases participants' human capital, beneficiaries become more employable and more productive once employed, which would be reflected in both higher employment levels, more persistence, and higher labor earnings levels for those employed. Alternatively, the program may not have an effect on human capital and thus it would not change beneficiaries' productivity, but it may be successful in contacting beneficiaries with future employers. In this case, we could expect higher employment but not higher earnings. The results from employment transitions indicate that the program operates by helping individuals keep their jobs once they are employed rather than by helping them find a job, and this is compatible with a situation in which the program enhances the productivity of participants rather than just providing the means to find new jobs. Moreover, the results on earnings bounds indicate that beneficiaries obtain higher wages once employed. Taken together, these results suggest that the program was successful in increasing the human capital of participants rather than (or in addition to) providing contacts or formal intermediation, or facilitating better matches. Concurrently, the evidence signals that these programs can provide other indirect benefits that are not usually accounted for as positive effects, such as reductions in welfare dependency and increases in the use of consumer credit.

This paper adds to the body of evidence on the impact of youth training program in developing countries and to the literature on active labor market policies in general. We also illustrate how useful experimental evaluations can be carried out even with small sample sizes $(\mathrm{N}=407)$ by combining them with rich administrative records that offer precise measurements of the outcomes of interest and their dynamics over long periods of time. The use of this type of data is still relatively uncommon in studies on developing countries. Moreover, this type of data also allows us to further probe the mechanisms through which the program operates by studying the dynamics of employment transitions. Finally, we also examine further potential effects of training programs

\footnotetext{
${ }^{2}$ It should be noted that the type of consumer credit that program participants could gain access to is, mostly, credit card debt, and some small payroll-based bank loans. Low-wage individuals in Argentina have low caps on the amount of debt they can take on through these channels, which implies that this type of credit is very unlikely to lead to debt-induced poverty traps and problems with spiraling repayments as in other countries such as the United States (White, 2007; Lusardi and Tufano, 2009).
} 
beyond employment and earnings, such as welfare participation and consumer credit use.

This papers is organized as follows: Section 2 describes the program and the random assignment process of potential beneficiaries to the treatment and the control group. Section 3 describes the data sources and the variables in the analysis. It also presents an analysis of baseline characteristics and experimental balance in the sample, and details the estimation strategy for the empirical results. Section 4 presents the empirical results on labor market outcomes and welfare use, and Section 5 presents the results on consumer credit use. Section 6 discusses these results and provides some concluding remarks.

\section{Program Description and Experimental Design}

\subsection{Program Description}

entra21 is a regional initiative of job training programs for low income youth in Latin America. The program is financed by the Multilateral Investment Fund (MIF, based in Washington, DC) and administered at the regional level by the International Youth Foundation (IYF). IYF partners with local organizations, mostly in the private sector (non governmental organizations, professional and business associations), which are the program's implementers. The program specifically targets vulnerable, unemployed youths who have some secondary schooling. It differs in some aspects from the training programs in Latin America mentioned in the introduction. Although governments can participate in its implementation, one of the hallmarks of the program is the private sector's very active involvement in its various project components, especially in terms of influencing the programs' training methods and curricula. In addition to not being a national program, it is usually smaller, and more costly than the typical government program.

entra21 was implemented in several countries in the region. The local organization in charge of the version of the program examined here is the Agencia para el Desarrollo Económico de la Ciudad de Córdoba (ADEC), a pubic-private non-profit set up by professional and business associations and Cordoba's Municipality. ${ }^{3}$ ADEC executed the program, with funding from MIF, IYF, the government of the province of Cordoba and the Municipality of the city of Cordoba. ADEC established partnerships with other governmental and civil society organizations to implement Phase II of the entra21 program, and with the Municipality's Secretaría de Desarrollo Social y Empleo (SDSE) and the province's Ministerio de Desarrollo Social (MDS), which provided logistic support for the program.

The program's main objective is to improve the employment opportunities of at-risk youth by building their technical skills and life-skills through courses and work experience in the private sector. Program administrators highlight that entra21 aims to increase the probability of finding

\footnotetext{
${ }^{3}$ Cordoba is Argentina's second most populous province, and the metropolitan area of the city of Cordoba, the province's capital, is the country's second largest with about 1.3 million inhabitants, according to the 2010 Census.
} 
"good quality" jobs in the formal sector, with the objective of reducing joblessness and informality, which are very high among young and vulnerable individuals in the region. The local implementing agency in Cordoba set the program eligibility requirements along entra21's regional guidelines. To be considered eligible, individuals had to be unemployed or underemployed, between the ages of 18 and 30, be a high school dropout or graduate, and have a total family income below the poverty line.

entra21's higher cost (compared to other training programs in Latin America) is due to the number of training hours provided, which is greater than that of most training programs in the region. The training includes a regionally standardized classroom-based life-skills training module, as well as vocational training and internships coordinated with private sector employers. In addition to basic information, communications technology, and life skills training, the classroom component offered training in a specific profession, metier, or skill considered to be in demand by actual firms, as well as general labor market related skills. The participants also took part in an internship to acquire on-the-job skills. Courses were offered in the following fields: cooking and catering, sales and administration, and factory workers ("operarios"). Coursework was divided in different modules: 100 hours of technical classroom training, 64 hours of life skills training, and 16 extra hours which varied from basic skills to extra classroom technical training according to each type of course. Classroom training took place between mid-November and February 2011, and was followed by the internship phase (although several participants started internships before completing their coursework and did both concurrently). For the internship, firms were offered a small monthly monetary incentive from the municipal government to cover basic workplace insurance. The program was promoted as offering a free recruiting service for firms with no legal obligation of continuing an employment relationship after the end of the internship. Firms were required to employ the intern for up to 4 months, with a maximum of 20 hours per week, to pay a proportion of the minimum wage according to hours worked, to provide a workplace mentor, and to issue a written certificate of the work experience and training for the intern at the end of the period.

\subsection{Experimental Design and the Random Assignment Process}

We designed an experimental evaluation strategy for this first cohort of the Cordoba edition of entra21, in close coordination with the implementing agencies. Since there was only a limited number of places available and, from the onset, the program was expected to be over-subscribed, participants from the first cohort were assigned to a treatment or a control group through a public lottery. Individuals signing up for the program received a personal visit by a representative of the implementing agency who conducted a baseline survey to gather information on participants and to establish eligibility. In total, 560 young people applied to the program and 407 were eligible for the first cohort of the program.

All eligible applicants were entered in a lottery drawing which designated those who would be 
offered to participate in the program (the treatment group) and those who would become part of the control group. The lottery took place on November 9th, 2010 with the presence of public officials and members of the several organizations that collaborated in the program (training partners, business associations, etc.), and to stress the transparency of the process, a public notary certified the draw. Applicants were made aware of the method of assignment into treatment and control groups. They accepted the selection process' terms and provided consent for the implementing agency and the evaluation team to track their future labor market and other related outcomes for the purpose of the programs' impact evaluation.

From the 407 eligible applicants, 220 were randomly assigned to participate in the program through this public lottery (for an expected intake of about 200). The remaining 187 were excluded from the program. Out of the total of 220 assigned to treatment group, 178 participated in the program, while the 42 remaining either declined participation at the beginning of the training or could not be reached by the implementing agency. A total of 106 participants completed the training phase. In terms of power calculations, the small sample size for of 220 individuals in the treatment group and 187 in the control group only permits the detection of relatively large effects in employment - about 8 percentage points, which amounts to an effect size of 0.30 . The strategies to maximize the statistical power of the estimates are discussed in the following section.

Given the timing of the program, we define the pre-program (or pre-treatment) period as up to the third quarter 2010 (Q3-2010), and the post-treatment refers spans from the second quarter of 2011 to the fourth quarter of 2013 (Q2-2011 to Q4-2013). We exclude from the analysis the months during which beneficiaries were undergoing training and participating in internships (the fourth quarter of 2010 and the first quarter of 2011).

\section{Data Sources and Baseline Characteristics}

\subsection{Data Sources}

We obtained detailed baseline (pre-program) information about the applicants and their households from the program's application form, which served as the program's targeting tool. We designed this application form as a short questionnaire based on the national periodical household survey. This survey was administered by the SDSE and the MDS to the 560 applicants. We use this information to verify the balance in observable socio-economic and demographic characteristics between the treatment and control groups for the 407 eligible individuals in our sample, and as controls in the estimations.

The main input to gauge the impact of the program on the expected outcomes is derived from administrative records. The SIPA (Sistema Integrado Previsional Argentino) is an integrated database setup jointly by the social security administration, ANSES (Administración Nacional de Seguridad Social), and the national tax authority (AFIP - Administración Federal de Ingresos 
Públicos), which records each registered workers' earnings and employment status on a monthly basis. The database was originally setup to track workers' "contributions" for their social insurance benefits (basically, payroll taxes earmarked for health and unemployment insurance, and payments into individual retirement accounts or the public pay-as-you-go pension system), and it has grown to include other related information such as participation in welfare programs. We matched each individual's national identification number to this database, and were able to obtain complete records on registered employment spells and the resulting gross labor earnings from January 2003 to November 2013. Since the oldest individuals in our sample were about 20 years old in 2003, we concentrate the analysis of employment and earnings from January 2008 onwards. The database was provided to us with the employers' tax identification number, although this identifier was masked for privacy reasons. We thus do not have detailed information about the employers, but we are able to tell whether individuals in our sample stay with the same employer over time.

Relying on these administrative records provides a detailed and precise record of employment status and earning levels for program participants, spanning 8 years before and 3 years after the program. As discussed above, most evaluations of training programs in Latin America rely on follow-up surveys that suffer from attrition and cover only short term effects. However, it should be stressed that by their nature, these administrative records only provide information on formal (or registered) employment and on earnings derived from this type of employment. It is likely that some individuals in our sample engage in informal employment, for which we do not have any information. Despite this limitation, the analysis presented below can still contribute to our understanding of the impact of youth labor training programs. On the one hand, the trade-off is between more detailed information on short term outcomes at one point in time (with some attrition and measurement error), and more complete and precisely measured information on a monthly basis that allows us to analyze outcomes in the short and medium run, and to study employment transitions and dynamics in general. On the other hand, the program's objective was to improve the employment opportunities of at-risk youth and to increase the probability of finding "good quality" (i.e., formal) jobs, so that the administrative records allow us to study the program's main intended outcome.

ANSES also manages the Asignación Universal por Hijo (AUH), Argentina's largest conditional cash transfer program, which targets informal workers and the unemployed. It provides a monthly payment according to the number of children in the household. This program began in 2009 and most of its beneficiaries are women. We also have information on AUH (welfare participation) matched by national identification number for women in our sample (none of the young male applicants were recorded as AUH beneficiaries in the period we study).

Finally, we collected information on consumer credit use from a range of sources. The first is the Central Bank of Argentina's database on individual debtors (Central de Deudores del Sistema Financiero, Banco Central de la República Argentina), a publicly accessible resource that records individuals' debts in the financial system. This database is available on the Internet, and the 
status of each individual in a given moment of time can be checked using a national identification number. The database contains information on bounced checks, frozen bank accounts from bankruptcy procedures, mortgages and consumer credit from banks and other regulated financial institutions. We construct an indicator stating whether individuals in our sample appear in this database as having consumer credit "in good standing," i.e., with no arrears and/or for which no foreclosure or recoup procedures have been started. In general, the types of consumer credit to which program participants (low-wage individuals) could gain access are credit card debt and some small payroll-based bank loans. Thus, we interpret the credit in good standing indicator as signaling that individuals are using credit cards or small loans on a regular basis. We constructed a second indicator on consumer credit use by using a credit rating agency (VERAZ-EQUIFAX). Each time an individual requests any form of formal credit, companies check the individual's records with one of these rating agencies. These records contain the number of checks for each individual every month, which we use as our second indicator of consumer credit use. These credit inquiries are made by bank and financial institutions, but also by shops selling goods on credit and by utilities leasing equipment (mobile phones, set top boxes, modems, etc.). We interpret this indicator as a proxy of consumer credit use by individuals in our sample. ${ }^{4}$

\subsection{Baseline Characteristics and Experimental Balance}

Table 1 provides descriptive statistics a series of individual and household characteristics and pretreatment outcomes for our sample, the 407 eligible applicants. As can be observed, around $29 \%$ of the program participants are male, the average age at the time of application was 23.55, and more than $70 \%$ have, at most, a high-school degree with no tertiary education. Most applicants were single $(69 \%)$ and only $19 \%$ had children. The p-values in the last column indicate that individual characteristics are balanced between the treatment and control groups.

Panel B in Table 1 presents summary statistics of pre-treatment levels for the main outcomes: formal employment status (an indicator variable equal to one if the individual appears in the administrative database as employed in a given month or quarter), gross labor earnings, and welfare participation. Average employment levels between the first quarter of 2003 and the fourth quarter of 2007 are low at $7 \%$ for the treatment group and about 5\% for the control group, which could be expected given the long time span of the administrative database (the average age of participants in 2003 was 16). The difference between the treatment and control groups for this variable is not statistically significant at standard levels ( $p$-value of 0.13 ). The same variable computed for the more immediate pre-treatment period, from the first quarter of 2008 to the third quarter of 2010, indicates higher employment levels of 0.16 and 0.12 for the treatment and control groups respectively. These formal employment levels are higher than for the previous period,

\footnotetext{
${ }^{4}$ The Appendix provides detailed definition of all outcome variables discussed in this section, as well as the different time frames we use for each outcome.
} 
which could be expected given the applicants' age, but still relatively low. This is compatible with the applicants' age and disadvantaged socio-economic background. The difference between the treatment and control groups for this period is statistically significant (p-value of 0.07), and a more in-depth analysis indicates that the difference was statistically significant at the $10 \%$ level for the last two quarters of 2009 and the first quarter of 2010, that is, only for 3 out of the 11 quarters before the program started (the evolution of this variable is depicted in panel A, Figure 1). We present the results from a multivariate test of balance in pre-treatment outcomes and characteristics below.

Panel B in Table 1 also presents summary statistics for earnings for the two pre-treatment periods for which we have information. These values are expressed in real Argentine pesos using January 2011 as the base month. Average monthly earnings were around 400 U.S. dollars during the period Q1-2008/Q3-2010 for individuals who were afterward selected into the treatment group, and about $\$ 366$ for the earlier period (Q1-2003/Q4-2007). There were no statistical differences in earnings for either period between subjects in the treatment and control groups who were employed. Finally, panel B in Table 1 also presents a measure of participation in the AUH cash transfer program, which started in late 2009. About $10 \%$ of women in both groups are recorded as having received the transfer in the first three quarters of 2010. The difference between the two groups is small and not statistically significant at standard levels.

Panel $\mathrm{C}$ in Table 1 presents pre-treatment summary statistics for the two consumer credit use measures for the periods for which they are available. The dummy of whether the applicant had credit in good standing for the second and third quarters of 2010 has an average of 0.09 for the treatment group and 0.06 for the control group. The two values are relatively low, and the difference between the two groups is not statistically significant. The average of our credit rating agencies' inquiries about applicants takes the value 0.11 for those in the treatment group and 0.12 for those in the control group for the period Q1-2008/Q3-2010, and the difference between the two groups is not statistically significant.

The last row of the table presents the p-value from an experimental balance test implemented on the variables in Table 1. The test is a likelihood-ratio test for equality of means between groups, which amounts to a version of Hotelling's T-squared generalized means test that allows for heterogeneous covariance matrices across groups. The p-value of 0.36 implies that we cannot reject the null hypothesis that the means of the variables in Table 1 are equal between the two groups when tested jointly. ${ }^{5}$ Given this result, and the public lottery that assigned applicants to the treatment and control groups, we attribute this difference to chance. There are 19 variables in the table, which implies that we can expect statistically significant differences to appear randomly, especially since our sample of 407 is relatively small. The observable individual characteristics

\footnotetext{
${ }^{5}$ The null for Hotelling's test and for the likelihood ratio test is that a set of means is equal between two groups. The former assumes that the covariance matrices in the two groups are the same, whereas the second allows for heterogeneous covariance matrices across groups.
} 
in panel $\mathrm{A}$ and in most pre-treatment outcomes appear to be balanced. Only three out of thirty pre-treatment quarters for which we have information appear to have a statistically significant difference in employment between the two groups. Moreover, as described in the previous section, the random assignment process was transparent and conducted by means of a public lottery certified by a notary. In order to gain precision in our estimates of the program's effects, we exploit these differences and include controls for pre-treatment employment levels, for other relevant pretreatment outcomes, and for individual characteristics in the regressions presented below (Duflo et al., 2008).

\subsection{Estimation}

Most of the results presented below are derived from OLS regressions where the regressor of interest is the indicator of whether an eligible applicant was randomly selected to participate in the program (treatment group) or not to participate in the program (control group). As discussed above, we include controls for individual characteristics and pre-treatment outcomes to control for minor chance imbalances in the randomization and to gain precision in our estimates. ${ }^{6}$ Most of the regressions presented below are of the form:

$$
Y_{i}=\alpha+\beta \text { TreatmentGroup } i+\delta X_{i}+\varepsilon_{i}
$$

where $Y_{i}$ indicates the outcome of interest (employment, earnings, credit status) for each individual $i$ in the sample, $\alpha$ is the constant, TreatmentGroup $i$ the indicator for being assigned to the treatment group (TreatmentGroup $=1$ ) or the control group (TreatmentGroup $=0$ ) and $X_{i}$ is a vector of individual characteristics (including the individual's age, sex, educational achievement and marital status), pre-treatment average employment for the period Q1-2008/Q3-2010 (included in all regressions), and the pre-treatment level of the dependent variable $Y_{i}$. The estimate of $\beta$ from regressions of this type corresponds to an intention to treat (ITT) estimator. We also carry out an analysis of heterogeneous effects by sex and by age group for some of the outcomes of interest by including interactions between the treatment group indicator and the relevant variables.

For the main outcomes summarized in Table 2, we also computed the effect of the program from regressions of the outcomes of interest as a function of actual participation in the program, $D$, of the form: $Y_{i}=\alpha+\beta D_{i}+\delta X_{i}+\varepsilon_{i}$, with participation $D$ instrumented by the random assignment variable TreatmentGroup. Since in the case of entra21 none of the individuals in the control group ended up participating in the program, this one sided non-compliance implies that the estimate of $\beta$ in the instrumental variables regression captures the treatment on the treated (TOT) effect of the program (Angrist et al., 1996). This amounts to up-scaling the ITT effects by

${ }^{6}$ When we exclude these controls and conduct simple comparisons of means between the treatment and the control groups, the results are qualitatively the same and quantitatively very similar for all outcomes discussed below, although there are some minor losses in precision in some cases. 
the first stage effect of the instrument on the participation variable. ${ }^{7}$ However, we follow most of the training evaluation literature and concentrate the discussion on the ITT effects. On the one hand, ITT is arguably the policy relevant parameter: since in most cases individuals are free to decide whether to take up a program or not, ITT provides policy makers with the effect of offering a program. Moreover, the selection of individuals into the program after the random assignment and the different alternatives for defining actual participation (e.g., some training, all the training phase, training and internship phases, etc.) complicates the interpretation of the TOT effects (Flores et al., 2012; Hirshleifer et al., 2014).

The analysis presented below presents the effect of the program on the main outcomes of interest for different post-treatment time frames. The program's assignment lottery was conducted in November 2010. The training started shortly afterward and was completed by February 2011. Most participants had completed their internships by March 2011. In keeping with the analysis of programs of this type, we consider observations up to the third quarter of 2010 as the pre-treatment period, and exclude from the analysis the fourth quarter of 2010 and the first quarter of 2011, when participants were undergoing training and/or internships. ${ }^{8}$ We carry out the analysis in terms of short run effects, which refer to the first half of our post-treatment period (the quarterly average outcomes for the period between the second quarter of 2011 and the third quarter of 2012, and the effect computed for outcomes in the third quarter of 2012); the medium run effects, which refer to the second half of the post-treatment period (the quarterly average of outcomes for the period between the fourth quarter of 2012 and the fourth quarter of 2013, as well as outcomes from the fourth quarter of 2013 only); and the average effect over the whole period of analysis (from the second quarter of 2011 to the fourth quarter of 2013).

\section{Employment, Labor Earnings and Welfare Participation}

\subsection{Employment Levels}

Training programs are designed to build human capital and foster the acquisition of skills, and their main expected outcome is improvement employment. However, these programs can also facilitate the contact of beneficiaries with the labor market, providing work experience, implicit or explicit labor market intermediation, contacts and references for future employment. These effects could be present even if the programs fail to build or reinforce beneficiaries' skills and human capital. However, distinguishing between these two set of effects is not evident. This section summarizes basic results on the impact of entra21 on employment levels, and then builds on estimates of the program effects on labor earnings and employment transitions to discuss which of these effects are

\footnotetext{
${ }^{7}$ A total of 106 out of 220 individuals in the control group completed all phases of the program, so the scaling up factor is 0.481 . This first stage effect of $Z$ on $D$ is significant at the $1 \%$ level.

${ }^{8}$ All the results presented below are robust to the exclusion of the second quarter of 2011 from the analysis, when a minority of participants were still engaged in the program's internships.
} 
at play in this program.

Table 2 presents the impact of the program on the main outcomes of interest for the time frames detailed above. Panel A presents the main benchmark results for employment. The results in the first column indicate that the program was successful in increasing formal employment in the short run: individuals in the control group exhibit a 7.96 percentage points higher probability of being in formal employment over this period (significant at the $5 \%$ level), which represents a $31.8 \%$ increase with respect to the control group's mean rate. This short term effect is even stronger when we compute it for the middle point of the post-treatment period, the third quarter of 2012: the difference is 10.2 percentage points, a $41.5 \%$ increase with respect to the control group.

The estimates in the third and fourth columns of panel A in Table 2 indicate that these short term effects dissipate in the medium run. The effects for the Q4-2012/Q4-2013 average and for the endpoint of the whole period, the fourth quarter of 2013, are still positive but lower (0.0434 and 0.0382 respectively) and not statistically significant at standard levels. The combination of strong short term effects and weaker medium run effects still results in a positive and significant effect (at the $10 \%$ level) of 6.91 percentage points for the overall period, as indicated by the coefficient in the fifth column of the table. This represents a still sizable difference of $25.1 \%$ with respect to the control group mean of $27.52 \%$ for the formal employment variable. As expected from the first stage coefficient, the impact is almost twice as high for the TOT estimates, and these results have the same pattern of statistical significance as the ITT effects.

These baseline results for employment seem to indicate that the effects of the program tend to fade over time. This may not be true for all participant groups. For instance, evidence from existing evaluations of training programs in Latin America indicate disparities by gender and by age-group. Table 3 presents a breakup of the previous results for formal employment along these dimensions, including interactions in the main regression. Panel A in that table presents the ITT estimates of program impact on employment by gender. The coefficient on the treatment group indicator captures the difference between women in the treatment group and women in the control group, and these differences are relatively small (between -3.78 and 1.54 percentage points, depending on the time frame considered) and not statistically significant. The coefficient on the men indicator, in turn, captures the difference in employment between men and women in the control group, and while this coefficient is larger in the medium run (9.27 percentage points for the average over Q4-2012 and Q4-2013, and 7.56 for Q4-2013), it is still not statistically significant. The coefficient on the interaction term between the treatment group indicator and the male applicant indicator is statistically significant at the $1 \%$ level for all the post-treatment sub-periods analyzed (except of Q4-2013, at the 5\% level), and these coefficients are remarkably stable over time. The sum of the coefficient on the interaction, on the treatment group indicator and on the men indicator, represents the difference in employment between men in the treatment group and women in the control group. These are very large, ranging from 26.86 percentage points in the short run (first column, significant at the $1 \%$ level) and 29.19 in the medium run (third column, statistically 
significant at $1 \%$ ), with a difference of 21.48 percentage points over the whole post-treatment period (fifth column).

The results in panel $\mathrm{B}$ of Table 3 indicate that there are no large nor statistically significant differences between older participants (25 to 30 at the baseline) in the treatment group and the control groups. The coefficient for the younger group dummy (those 18 to 24 at the baseline) indicate that there are no significant differences in employment between the two age groups in the control group. However, the sum of the three coefficients (the younger group indicator, the treatment group indicator, and the interaction between the two) reveals that, in the short run, the difference between younger participants in the treatment group and older individuals in the treatment group is 15.39 percentage points and significant at the $1 \%$ level. The same difference in the medium term is 9.57 and not statistically significant, and these two effects result in a difference of 12.74 percentage points (statistically significant at the $5 \%$ level) between these groups for the entire post-treatment period.

These heterogeneous results complement the main results for formal employment from panel A in Table 2: they show that effects are stronger for male and for younger participants over the whole period than the average effect for the full sample, and they remain strong for male participants in the medium run.

\subsection{Monthly Labor Earnings}

Another important dimension of the impact of labor training programs is their potential effect on real labor earnings. Panel B in Figure 1 presents the evolution of earnings (in real January 2011 Argentine pesos) from the first quarter of 2008 to the fourth quarter of 2014 . There appears to be a post-treatment divergence between the two groups, with substantially higher levels and steeper trajectories for those in the treatment group. Panel B in Table 2 reports the ITT estimates of the program's effects on real earnings for the same sub-periods discussed earlier. The pattern of results is similar to that of formal employment: there are sizable and statistically significant effects in the short run: differences of 332.23 pesos (about $\$ 83$ USD, significant at the $1 \%$ level) for average monthly earnings for Q2-2011/Q3-2012, and of 328.18 pesos (about \$82 USD, significant at the $5 \%$ level) for the third quarter of 2012 (first and second column). The effects on average earnings are still positive but smaller and not statistically significant for Q4-2012/Q4-2013 and for Q4-2013 (179 and 98.96, third and fourth column), with an average effect for all the post-treatment period of 265.19 pesos (about $\$ 62.3$ USD), significant at the $5 \%$ level (fifth column). ${ }^{9}$ Panels A and B in Table 4, in turn, present the heterogeneous impact of the program on monthly earnings by gender and by age group, respectively. While there are almost no statistically significant differences by age group, the impact of the program on earnings is markedly stronger for men than it is for women,

\footnotetext{
${ }^{9}$ The same pattern of results holds when we consider additional earnings aggregates, for instance, bounding extreme values at the 99th percentile of the earnings distribution in the control group, or using an inverse hyperbolic sine transformation as in Hirshleifer et al. (2014) (results not reported).
} 
as witnessed by the coefficients of the treatment group and men indicators interactions in panel A. All of these coefficients are large and statistically significant, indicating substantial differences in earnings between men in the treatment group and women in the control group. The coefficients on the treatment group indicator and on the male indicator are small and not statistically significant in the five regressions presented, indicating the lack of differential effects between mean in the treatment and control groups, and between men and women in the control group.

The estimates of the program's effects on earnings presented in Tables 2 (panel B) and 4 (panels $\mathrm{A}$ and $\mathrm{B}$ ) have a mechanical relationship with those for employment. Increases in total labor earnings can be caused by higher employment levels, by increases in earnings for those already employed, or by both. The total impact is a combination of productivity gains and changes in employment composition. If the program increases participants' human capital, beneficiaries become more employable and more productive once employed, which would be reflected in both higher employment and higher labor earnings levels for those employed. Alternatively, the program may not have an effect on human capital and thus it would not change beneficiaries' productivity, but it may be successful in contacting beneficiaries with future employers. In this case, we could expect higher employment but not higher earnings. Since the estimates we presented so far are based on outcomes that include zero incomes (i.e., those who are not employed), the positive impact on earnings alone does not allow us to separate the employment effect from any direct impact on earnings.

We follow Attanasio et al.'s (2011) approach, ${ }^{10}$ which makes additional assumptions based on the distribution of earnings and employment for the control group in order to estimate the program's impact on productivity. ${ }^{11}$ They divide the sample of individuals in four groups: those who work regardless of program participation (what Angrist and Imbens, 1994, refer to as "always takers"), those who would never work, those who begin to work because of the program (what Angrist and Imbens, 1994, label as "compliers") and those who stop working because of the program. Randomization ensures that the size of each group is independent of assignment to treatment. Using the monotonicity assumption, individuals who would work without the program would also work if they did the training. This allows us to decompose the effect of the program as the sum of the effect on the earnings of compliers plus the effect on the earnings of always takers. We can estimate the productivity gain from the program and the change in composition. The previous results show that average earnings increased, but we cannot conclude whether this is due to productivity gains or to changes in employment. The bounds are determined by estimating the productivity effects and the distribution of wages in the control group, and they are presented in panel $\mathrm{C}$ of Table 4. The calculated bounds for the average earnings over the whole post-treatment period (fifth column) are large and positive, but the lower bound is negative. To narrow the

\footnotetext{
${ }^{10}$ Lee (2009), Chen and Flores (2012) and Blanco et al. (2013) have proposed several alternatives that separate these effects and obtain bounds for treatment effects on labor earnings in the case of training and similar active labor market policies.

${ }^{11}$ The procedure to construct these bounds is derived in Appendix B of Attanasio et al. (2011).
} 
interval, we also consider an additional assumption: non-program earnings of those who always work are at least as high as the non-program earnings of individuals who are no longer unemployed. The bounds with this additional assumption are tighter, and indicate an effect on monthly earnings between 457.97 and 1238.93 pesos for the average over the whole post-treatment period.

We interpret this result as limited evidence that the program increased earnings for those employed, over and above its effect on employment. This evidence and that of positive employment effects seems to support the hypothesis that the program managed to increase beneficiaries' productivity.

\subsection{Employment Transitions}

The discussion so far is in line with that of most studies of training programs in Latin America: while we are able to gauge the effect over a longer period, we presented the impact of the program at one or two post-treatment periods using follow-up information. However, the rich administrative data we use can be further exploited to establish some of the mechanisms through which the program generates its positive impacts on formal employment. To do this, we use the full panel data structure of monthly information from the administrative records to estimate models of employment transitions, spells and related outcomes. ${ }^{12}$

Table 5 presents the results from an analysis of the program's impact on simple indicators of employment transitions and individual aggregates of employment over time. Panel A presents the results from a regression where the dependent variable indicates whether the individual was employed in any month within each period, for the first half of the post-treatment period (first column), the second half (second column), and the whole treatment period (third column). Focusing on the latter, we observe that $50.8 \%$ of individuals in the control group were formally employed for at least one month over the 11 quarters considered, and that this proportion was 9.83 percentage points higher for the treatment group (a $19.4 \%$ increase, significant at the $5 \%$ level). The same effect appears for the two halves of the post-treatment period, and it is again stronger in the short term.

The dependent variables in the regressions presented in panels B and C of Table 5 represent basic summaries of employment transitions. In panel B, the dependent variable is an indicator of whether individuals ever entered formal employment in each period, whereas the dependent variable in panel $\mathrm{C}$ is an indicator of whether individuals ever left formal employment. The coefficients for the overall post-treatment period (third column) are positive for both dependent variables, but relatively small and not statistically significant.

The dependent variables in Table 5 were summary statistics of employment transitions over the post-treatment period. We also estimate a dynamic model using the full monthly panel data

\footnotetext{
${ }^{12}$ Card et al. (2011) also carry out an analysis of this type, although theirs is based on retrospective information collected at a single point in time after the program. They reconstruct employment spells and transitions from this information.
} 
on employment. We follow Card et al. (2011) and estimate a simple dynamic model of the form:

$$
Y_{i t}=\alpha+\beta \text { TreatmentGroup } \times Y_{i, t-1}+\rho \text { TreatmentGroup } \times\left(1-Y_{i, t-1}\right)+\theta Y_{i, t-1}+\delta X_{i}+\phi_{t}+\varepsilon_{i t}
$$

where $Y_{i t}$ is employment, the outcome of interest (taking values 0 or 1 ), $Y_{i, t-1}$ is the same outcome in the previous month, and TreatmentGroup $i$, as above, is the indicator for being assigned to the treatment group. The coefficient $\beta$ on the interaction between the treatment group indicator and the outcome in the previous period captures the degree of persistence of formal employment (i.e., the probability of continuing in employment once the individual is employed). The coefficient $\rho$ on the interaction between the treatment group indicator and the transformation $1-Y_{i, t-1}$ (which indicates whether individual $i$ was not employed in the previous period) captures what we label as an access effect (i.e., the probability of entering employment when the individual is unemployed). The coefficient $\theta$ captures the overall degree of dependence of current employment status on that of the previous period for individuals in both the treatment and the control group. We also include controls $\phi_{t}$ for every month, a set of individual characteristics $X_{i}$ as controls, and we cluster standard errors by individual.

The results from this model are presented in Table 6 for the first half of the post-treatment period (first column), the second half (second column), and the whole treatment period (third column). Panel A presents the results for the full sample. Besides a strong dependence of current employment with respect to the previous month, the persistence and access effects are small and not statistically significant, with the exception of the persistence effect for the short run of 0.0346 , significant at the $10 \%$ level.

Panel B presents the results of the same model when restricting the sample to female eligible applicants. As in the previous panel, only one of the coefficients is statistically significant, the persistence effect over the second half of the post-treatment period. In contrast with the aggregate results, this coefficient of -0.0362 (significant at the $10 \%$ level) indicates a small negative effect for women in the medium term.

Panel C, in turn, presents the results for men in our sample. The short term persistence effects are much larger (0.0996) and significant at the $1 \%$ level. While the persistence effect for the second half of the post-treatment period is close to zero and not significant, the short term effect still drives a positive and statistically significant effect of 0.0522 for the whole post-treatment period. The pattern is similar for younger individuals (panel D), although the short term persistence effect is weaker than that for men (0.0560), and the resulting coefficient for the whole period is smaller (0.0263) and not statistically significant. Finally, the treatment does not seem to have altered significantly the employment transitions of older individuals (panel E).

These results indicate that the program operates by helping individuals keep their jobs once they are employed rather than by helping them find a job, but only in the short term. This is compatible with a situation in which the program enhances the productivity of participants rather 
than just providing the means to find new jobs.

\subsection{Welfare Participation}

As discussed above, we set out to analyze the mechanisms through which the program operates and to establish the program's effects on outcomes beyond employment and labor earnings. The first additional outcome of interest is welfare participation. The administrative records contain information on participation in the Asignación Universal por Hijo (AUH), a large cash transfer program targeted to unemployed and informal workers with children, received mainly by women.

Since we restrict the sample to women, we have a limited number of observations. The program did not have a significant effect on average participation in AUH on average over the period of study (results not reported). We construct an alternative measure that proxies welfare dependency in addition to participation. We construct a dummy that takes value 1 if a woman in our sample is a beneficiary of AUH over the whole period of time we consider, and zero otherwise. The results for this outcome are shown in Table 8, panel A. About 12.9\% of women in the control group received the transfer over the first half of the post-treatment period (Q2-2011/Q3-2012, first column), $16.94 \%$ over the second half of the post-treatment period, and $10.48 \%$ over the whole period (third column). The differences in this measure of welfare participation between women in the treatment and control groups is close to zero and not statistically significant in any of the sub-periods. The same estimates are broken down by age group and presented in panel B of the same table. These additional results indicate that the program reduced long spells of welfare participation for the overall post-treatment period for younger women in the treatment group, with a coefficient on the interaction of 0.1147 significant at the $1 \%$ level. These results are directly connected with the employment results presented above: the AUH eligibility rules imply that formally employed individuals are generally disqualified for the benefit, and thus the reduction in welfare participation for younger women could reflect the increase in employment for the younger group.

\section{Consumer Credit Use}

Finally, we study the impact of the entra21 youth training program on consumer credit use, which to the best of our knowledge has not been considered a direct or indirect outcome of this type of program in the existing literature. Previous work has often concentrated in the opposite direction - how access to credit by means of specific government programs or micro-credit may foster selfemployment or entrepreneurship (see for instance Premand et al., 2012, and Duflo et al., 2013). In this literature, credit constraints reduce the demand for training and for productive investment and reduce entrepreneurship initiatives, which motivates public interventions.

However, one of the main features of formal employment in Argentina, and one that makes 
it especially appreciated by workers, is that it provides a high degree of job security. ${ }^{13}$ Formal employment is legally open-ended (as opposed to employment at will in the United States), and terminations are costly, involving relatively generous severance payments and frequently leading to legal challenges in special labor courts. A consequence of employment stability is that it provides a stable stream of income. We can illustrate this with information from the national household survey's rotating panel structure (Encuesta Permanente de Hogares), which provides four repeated observations at six month intervals for the same individuals. For the 2005-2006 period, dependent workers in the age-group of entra21's beneficiaries who were formally employed in the four observations had average earnings of 834 Argentine pesos with a standard deviation over time of 221 pesos, whereas those who were informally employed in the same four time periods had average earnings of 361 pesos with a standard deviation of 141 pesos. The coefficient of variation of earnings over time for the second group (0.391) is almost $47.5 \%$ higher than that for the first group (0.265).

This income stability may reduce credit constraints, but even in a simple two period model of credit with no constraints, higher, less volatile and more verifiable earnings in the first period would increase borrowing in the second period. One reason for this type of effect is that income from formal employment (which must be paid into an employer-sponsored savings account at a bank) is easier to verify and to collateralize than most other income sources. Coelho et al. (2012) illustrate the latter effect in Brazil. Banks were allowed to offer loans with repayment through automatic payroll deduction, and this resulted in a reduction in interest rates and higher volumes of consumer credit. Gutierrez (2014), in turn, shows that formal labor contracts in Mexico reduce wage fluctuations and serve as income smoothing mechanisms against productivity and other shocks. entra21's positive impact on formal employment and earnings could thus facilitate the use of consumer credit, which would imply that the effects of the training go beyond those currently explored by the literature. Insofar as it helps to reduce risk, a central feature in the life of vulnerable groups, consumer credit use constitutes a relevant outcome of programs like entra21 and others in the regions that have found positive effects on formal employment (Attanasio et al., 2011; Card et al., 2011).

To study the relationship between training, formal employment and the use of consumer credit, we matched individuals in the treatment and control groups with administrative records on consumer credit from the EQUIFAX-VERAZ credit rating agency and from the Central Bank's registry of consumer debt, as detailed in section 3.

The evolution of the credit in good standing indicator from the first quarter of 2008 to the fourth quarter of 2013 is depicted in Figure 1 (panel C). There is an apparent widening of the

\footnotetext{
${ }^{13}$ This is supported by the results from a module on labor informality included in the 2005 edition of the national household survey, EPH. Only $5 \%$ of those in informal employment stated that they were offered to work formally (i.e., as registered employees) in the same job but came to an agreement to be hired informally instead "to receive a higher salary or better benefits." The remaining $95 \%$ stated that their employers did not offer the option to work formally, which they preferred - job security was paramount among the advantages of this type of employment relationship (MTEySS, Banco Mundial and INDEC, 2007).
} 
gap between the treatment and control groups, and this is confirmed by the regression results for this outcome, which are presented in panel C, Table 2. Being selected into the treatment group induces a positive and significant increase in the credit in good standing indicator, although this effect is only statistically significant in the short run. For the average between the second quarter of 2011 and the third quarter of 2012, the difference is 0.0455 (significant at the $5 \%$ level), and it is higher when we compute the effect for the third quarter of 2012 (0.0674, significant at the 10\% level). For the second half of the treatment period, the effect is still positive, but about half of that for the short run, and not statistically significant. The same is true for the effect over the whole post-treatment period. However, as for employment and earnings, there seem to be some heterogeneous effects. The results in the first three columns of Table 9 indicate that the credit in good standing indicator is significantly higher over the whole post-treatment period for men (panel B) and for younger participants (panel C), and both results are present for the two halves and for the whole post-treatment period.

Finally, panel D in Table 2 presents the estimates of the program's effect on the monthly average number of credit inquiries made to credit rating institutions about individuals in our sample. The results indicate that the program only affected this indicator in the very short run: those in the treatment group have a higher number of inquiries $(0.0776$, significant at the $5 \%$ level) for the average of the first part of the post-treatment period, but the coefficient is virtually zero when evaluated for the third quarter of 2012, the midpoint of the post-treatment period. The coefficients for the second half of the treatment period and for the overall treatment period are small and not statistically significant. While these are the effects for the overall sample, the results in the fourth to sixth columns of Table 9 also indicate the presence of heterogeneous effects for this outcome. The pattern is similar to that of credit in good standing and other outcomes: the number of credit inquiries over the whole post-treatment period is significantly higher for men (panel B) and for younger participants (panel $\mathrm{C}$ ).

Program participants thus exhibit a higher probability of having requested consumer credit, and a higher probability of holding bank debts in good standing, in the short run. The pattern of these effects over time is similar to that of the impact of the program on employment and earnings,

which reinforces the hypothesis that formal employment caused higher levels of consumer credit use. The effects are stronger and more evenly distributed over the whole post-treatment period for male participants and for younger participants.

\section{Discussion and Conclusions}

The results for entra21 discussed in this paper indicate that the program successfully increased the employment levels and the earnings of beneficiaries over the short run, with sizable gains that persist over the medium run for men.An analysis of employment transitions indicates that the program operates by helping individuals keep their jobs once they are employed rather than by 
helping them find a job. Moreover, an analysis of earnings bounds indicates that beneficiaries obtain higher wages once employed. Both results are compatible with a situation in which the program enhances the productivity of participants rather than just providing the means to find new jobs, and suggest that the program was successful in increasing the human capital of participants rather than (or in addition to) providing contacts or formal intermediation, or facilitating better matches. Concurrently, the evidence signals that these programs can provide other indirect benefits that are not usually accounted for as positive effects, such as reductions in welfare dependency and increase in the use of consumer credit.

These positive effects, that appear larger than those for most programs of this type in Latin America, must be gauged against the programs' costs. As highlighted in the description of the program, entra21 entailed higher costs as compared to other training programs in the region that targeted the same beneficiary groups. According to program documentation, the cost of operation per trainee in the Cordoba program analyzed here was approximately 1722 USD, more than twice the cost of the programs for Colombia (750 USD, Attanasio et al., 2011) and the Dominican Republic (330 USD; Card et al., 2011). The average gain in monthly earnings from the program was 265.19 pesos or about 66.3 USD (last column of Table 2, panel B), and the simplest measure of return (with no discounting) indicates that it took about 26 months to recoup the cost of the program.

We can compare the costs and benefits from entra21 to those obtained by Attanasio et al. (2011) for the Colombian initiative. We compute our cost-benefit analysis by matching their scenario in which they assume that the gains from the program are permanent but that they depreciate at a 10 percent annual rate. Like Attanasio et al. (2011), we assume that the working life of applicants is 40 years and apply a $5 \%$ yearly discount rate. The Colombian program was significantly less expensive, at 750 USD per person, compared to 1722 USD per person for entra21. Despite the difference in costs, the driving factor of this large difference in returns is the effect of the program: the Colombian program results in higher earnings of about 17.6 USD per month (for women), whereas our estimate for entra21 yields about 66.3 USD per month. ${ }^{14}$ Attanasio et al. (2011) compute a life cycle net benefit of 666 USD for women, which corresponds to an internal rate of return of 21.6 percent. We compute a much higher gain of 3,835.30 USD for individuals in our sample, which yields an internal rate of return of $67.29 \%$. The availability of longer term high frequency administrative data allows us to refine these estimates. For instance, the effect of the program declines between the first and the second half of the post-treatment period by about $20 \%$. Using this as a more realistic input for the discount rate yields a still substantial but lower internal rate of return of $48.7 \%$, which falls even further when using alternative measures of depreciation (for instance, to $11.5 \%$ with a more conservative implicit depreciation of $40 \%$ ).

While we ignore additional benefits from formal employment, which we cannot quantify, our

\footnotetext{
${ }^{14}$ These estimates ignore additional potential costs and issues such as the job displacement of others by program beneficiaries or the welfare cost arising from distortionary taxes to finance the intervention.
} 
results on consumer credit use indicate that the overall positive effects of the program might be substantially higher, and they might also imply some externalities. For instance, Hsu et al. (2014) find that unemployment insurance in the United States reduces deadweight losses from loan defaults and expands access to credit, because the program reduces beneficiaries' defaults on mortgage debt and a subsequent fall in the interest rate because of the reduction in credit risk.

The analysis and the results allow us to draw some conclusions. The evaluation of training programs should explicitly attempt to follow beneficiaries over a longer period of time than the usual one or two years. Our results for the whole sample coincide with other similar programs evaluated over similar time periods in the region, but these average employment gains dissipate in the longer run. This contrasts with the available evidence for developed countries, which typically finds positive medium-term impacts of training programs that often appear ineffective in the short term (Card et al., 2010). Moreover, our analysis illustrates the usefulness of experimental evaluations even with small sample sizes $(\mathrm{N}=407)$, when combined with rich administrative records that offer precise measurements of the outcomes of interest and their dynamics over long periods of time. The analysis also illustrates how this type of data allows us to further probe the mechanisms through which the program operates, by studying the dynamics of employment transitions. The use of this type of data is still relatively uncommon in studies on developing countries, but it could provide fruitful results in the future. 


\section{References}

[1] Angrist, J., Imbens, G., and Rubin, D. (1996). "Identification of Causal effects Using Instrumental Variables., "Journal of the American Statistical Association, vol. 91(434), pages 444-455.

[2] Angrist, J. and Imbens, G. (1994). "Identification and Estimation of Local Average Treatment Effects," Econometrica, vol. 62(2), pages 467-475.

[3] Attanasio, O., Kugler, A. and Meghir, C. (2011). "Subsidizing Vocational Training for Disadvantaged Youth in Colombia: Evidence from a Randomized Trial," American Economic Journal: Applied Economics, vol. 3(3), pages 188-220.

[4] Blanco, G., Flores, C. and Flores-Lagunes, A. (2013). "Bounds on Average and Quantile Treatment Effects of Job Corps Training on Wages," Journal of Human Resources, Vol. 48, No. 3, pp. 659-701.

[5] Card, D., Kluve, J. and Weber, A. (2010). "Active Labor Market Policy Evaluations: A Meta-Analysis," Economic Journal, vol. 120(548), pages F452-F477.

[6] Card, D., Ibarrarán, P., Regalia, F., Rosas-Shady, D. and Soares, Y. (2011). "The Labor Market Impacts of Youth Training in the Dominican Republic: Evidence from a Randomized Evaluation," Journal of Labor Economics, vol. 3(2), pages 267-300.

[7] Chen, X. and Flores, C. (2012). "Bounds on Treatment Effects in the Presence of Sample Selection and Noncompliance: The Wage Effects of Job Corps," Mimeo, Cal Poly.

[8] Coelho, C. A., De Mello, J. M. P. and Funchal, B. (2012). "The Brazilian Payroll Lending Experiment," The Review of Economics and Statistics, Vol. 94, No. 4, Pages 925-934.

[9] Duflo, E., Glennerster, R., and Kremer, M. (2008), "Using Randomization in Development Economics Research: A Toolkit," Handbook of Development Economics, vol. 4.

[10] Duflo, E., Banerjee, A., Glennerster, R. and Kinnan, C. G. (2013). "The Miracle of Microfinance? Evidence from a Randomized Evaluation," NBER Working Paper No. 18950.

[11] Flores, C., Flores-Lagunes, A., Gonzalez, A. and Neumann, T. (2012). "Estimating the Effects of Length of Exposure to Instruction in a Training Program: The Case of Job Corps," The Review of Economics and Statistics, vol. 94(1), pages 153-171.

[12] Gasparini, L., Cruces, G. and Tornarolli, L. (2011). "Recent trends in income inequality in Latin America," Economia 10 (2), 147-201, Spring. 
[13] González-Velosa, C., Ripani, L., and Rosas-Shady, D. (2012). "How Can Job Opportunities for Young People in Latin America be Improved?" Inter-American Development Bank: Labor Markets and Social Security Unit (SCL/LMK), Technical Notes No. IDB-TN-345.

[14] Gutierrez, F. H. (2014). "Acute morbidity and labor outcomes in Mexico: Testing the role of labor contracts as an income smoothing mechanism," Journal of Development Economics, Volume 110, Pages 1-12.

[15] Hirshleifer, S., McKenzie, D., Almeida, R. and Ridao-Cano, C. (2014). "The Impact of Vocational Training for the Unemployed. Experimental Evidence from Turkey," World Bank, Policy Research Working Paper 6807.

[16] Hsu, J. W., Matsa, D. A. and Melzer, B. T. (2014). "Positive Externalities of Social Insurance: Unemployment Insurance and Consumer Credit," NBER Working Paper 20353.

[17] Ibarrarán, P., Ripani, L., Taboada, B., Villa, J. and Garcia, B. (2014). "Life Skills, Employability and Training for Disadvantaged Youth: Evidence from a Randomized Evaluation Design," IZA Journal of Labor and Development 3 (10).

[18] Lee, D. (2009). "Training, Wages, and Sample Selection: Estimating Sharp Bounds on Treatment Effects," Review of Economic Studies 76 (3): 1071-1102.

[19] Lusardi, A. and Tufano, P. (2009). "Debt Literacy, Financial Experiences, and Overindebtedness," NBER Working Papers 14808.

[20] MTEySS, Banco Mundial and INDEC (2007). La informalidad Laboral en el Gran Buenos Aires. Una nueva mirada. Resultados del Módulo de Informalidad de la EPH. Ministerio de Trabajo, Empleo y Seguridad Social, Banco Mundial, and Instituto Nacional de Estadísticas y Censos, Buenos Aires, Argentina.

[21] Pallais, A. (2014). "Inefficient Hiring in Entry-Level Labor Markets," American Economic Review, forthcoming.

[22] Premand, P., Brodmann, S., Almeida, R., Grun, R. and Barouni, M. (2012). "Entrepreneurship Training and Self-Employment among University Graduates: Evidence from a Randomized Trial in Tunisia," World Bank Policy Research Working Paper 6285.

[23] Vezza, E. (2014). "Policy Scan and Meta-Analysis: Youth and Employment Policies in Latin America," CEDLAS Working paper 156, Universidad Nacional de La Plata.

[24] White, M. J. (2007). "Bankruptcy Reform and Credit Cards," Journal of Economic Perspectives, 21(4): 175-200. 


\section{Appendix A: Main Variables}

Random assignment: this variable indicates whether the individual was randomly assigned to participate in the training program (takes value 1 for the treatment group, 0 for the control group).

Completed training: dummy variable that indicates if an eligible individual participated and completed the training phase.

Formal employment: dummy by quarter that takes value 1 if a person was employed at least one month in the quarter.

- Average Q2-2011 to Q3-2012: average of the formal employment variable for these quarters - labeled as short term.

- Average Q4-2012 to Q4-2013: average of the formal employment variable for these quarters - labeled as medium term.

- Average Q2-2011 to Q4-2013: average of the formal employment variable for all the post-treatment period. Monthly earnings: Monthly earnings.

- Average Q2-2011 to Q3-2012: average of monthly earnings for these quarters (short term).

- Average Q4-2012 to Q4-2013: average of monthly earnings for these quarters (medium term).

- Average Q2-2011 to Q4-2013: average of monthly earnings for all the post-treatment period.

Consumer credit in good standing: indicator that takes value 1 if an individual's consumer credit status appears as "in good standing" - a value of 1 or 2in the Argentine Central Bank's "Central de Deudores" classification, and 0 otherwise.

- Average Q2-2011 to Q3-2012: average of the consumer credit in good standing variable for these quarters labeled as short term.

- Average Q4-2012 to Q4-2013: average of the consumer credit in good standing variable for these quarters labeled as medium term.

- Average Q2-2011 to Q4-2013: average the consumer credit in good standing variable for all the posttreatment period.

Number of credit inquiries: variable that indicates the number of quarterly credit enquiries for each individual made by firms (banks, utilities and stores selling on credit) to the credit rating agency EQUIFAX-VERAZ. The agency reports the individual's credit situation, credit rating and other related information.

- Average Q2-2011 to Q3-2012: average of the number of credit enquiries variable for these quarters - labeled as short term.

- Average Q4-2012 to Q4-2013: average of the number of credit enquiries variable for these quarters - labeled as medium term.

- Average Q2-2011 to Q4-2013: average of the number of credit enquiries variable for all the post-treatment period.

Asignación Universal por Hijo-AUH: indicator variable that takes the value 1 if a woman in the sample received the benefit continuously over a given period of time.

- Always Q2-2011 to Q3-2012: equal to 1 if a woman receives the benefit during the whole short term period.

- Always Q4-2012 to Q4-2013: equal to 1 if a woman receives the benefit during the whole medium term period.

- Always Q2-2011 to Q4-2013: equal to 1 if a woman receives the benefit during the whole post-treatment period. 
Table 1: Summary statistics: Individual characteristics at baseline and pre-treatment outcomes

\begin{tabular}{lccccccc}
\hline & \multicolumn{2}{c}{ Treatment } & \multicolumn{2}{c}{ Control } & \multicolumn{3}{c}{ Difference } \\
Variables & Mean (1) & SE & Mean (2) & SE & $(1)-(2)$ & SE & P-value \\
\hline A. Baseline survey data & & & & & & & \\
Male & 0.295 & 0.031 & 0.337 & 0.035 & -0.041 & 0.046 & 0.371 \\
Age & 23.545 & 0.238 & 23.797 & 0.263 & -0.251 & 0.354 & 0.478 \\
Incomplete elementary school & 0.036 & 0.013 & 0.027 & 0.012 & 0.010 & 0.018 & 0.583 \\
Complete elementary school & 0.077 & 0.018 & 0.053 & 0.016 & 0.024 & 0.025 & 0.338 \\
Incomplete high school & 0.277 & 0.030 & 0.326 & 0.034 & -0.049 & 0.046 & 0.284 \\
Complete high school & 0.327 & 0.032 & 0.332 & 0.035 & -0.004 & 0.047 & 0.927 \\
Incomplete tertiary level/college & 0.177 & 0.026 & 0.160 & 0.027 & 0.017 & 0.037 & 0.653 \\
Complete tertiary level/college & 0.068 & 0.017 & 0.059 & 0.017 & 0.009 & 0.024 & 0.701 \\
Children in the household & 0.191 & 0.027 & 0.246 & 0.032 & -0.055 & 0.041 & 0.179 \\
Single & 0.695 & 0.031 & 0.668 & 0.035 & 0.027 & 0.046 & 0.561 \\
Married/cohabiting & 0.232 & 0.029 & 0.273 & 0.033 & -0.041 & 0.043 & 0.344 \\
Divorced/separated & 0.045 & 0.014 & 0.037 & 0.014 & 0.008 & 0.020 & 0.688 \\
B. Administrative data & & & & & & & \\
Avg. employment Q1 2003/Q4 2007 & 0.069 & 0.012 & 0.046 & 0.010 & 0.024 & 0.016 & 0.135 \\
Avg. employment Q1 2008/Q3 2010 & 0.162 & 0.019 & 0.115 & 0.017 & 0.047 & 0.026 & 0.067 \\
Avg. quarterly earnings Q1 2003/Q4 2007 & $1,463.96$ & 88.44 & $1,351.15$ & 106.36 & 112.81 & 140.32 & 0.424 \\
Avg. quarterly earnings Q1 2008/Q3 2010 & $1,599.48$ & 83.75 & $1,513.60$ & 105.94 & 85.88 & 134.37 & 0.524 \\
Always AUH Q1 2010/Q3 2010 & 0.100 & 0.020 & 0.097 & 0.022 & 0.003 & 0.030 & 0.928 \\
C. Consumer credit (cred. rating agencies) & & & & & & & \\
Avg. credit good st. Q2 2010/Q3 2010 & 0.09 & 0.02 & 0.06 & 0.02 & 0.03 & 0.03 & 0.312 \\
Avg. credit inquiries Q1 2008/Q3 2010 & 0.11 & 0.01 & 0.12 & 0.01 & -0.01 & 0.02 & 0.733 \\
& & & & & & & 0.356 \\
Balance test p-value & & & & & & & \\
\hline
\end{tabular}

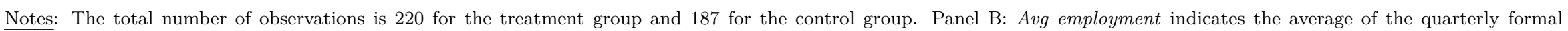

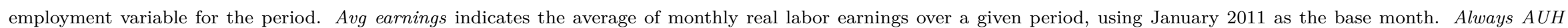
(Asignación Universal por Hijo) indicates receipt of this benefit every month in a given period. dummy that takes value 1 if a woman received AUH assistance during the entire

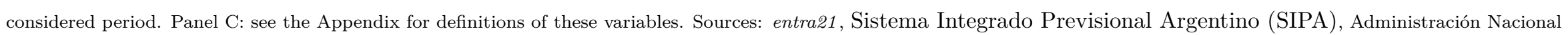
de la Seguridad Social (ANSES), Sistema Integrado Previsional Argentino (SIPA), Banco Central de la República Argentina and EQUIFAX-VERAZ. 
Table 2: Program impact, main results. Intention to treat and treatment on the treated

\begin{tabular}{|c|c|c|c|c|c|}
\hline & $\begin{array}{c}\text { Average } \\
\text { Q2-2011/Q3-2012 }\end{array}$ & Q3-2012 & $\begin{array}{c}\text { Average } \\
\text { Q4-2012/Q4-2013 }\end{array}$ & Q4-2013 & $\begin{array}{c}\text { Average } \\
\text { Q2-2011/Q4-2013 }\end{array}$ \\
\hline \multicolumn{6}{|l|}{ A. Formal employment } \\
\hline \multirow[t]{2}{*}{ Treatment group - ITT } & $0.0796^{* *}$ & $0.1020^{* *}$ & 0.0434 & 0.0382 & $0.0691^{*}$ \\
\hline & {$[0.0371]$} & {$[0.0465]$} & {$[0.0403]$} & {$[0.0450]$} & {$[0.0371]$} \\
\hline \multirow[t]{2}{*}{ Completed training - TOT } & $0.1641^{* *}$ & $0.2104^{* *}$ & 0.0895 & 0.0787 & $0.1433^{*}$ \\
\hline & {$[0.0762]$} & {$[0.0962]$} & {$[0.0831]$} & {$[0.0925]$} & {$[0.0769]$} \\
\hline Control group mean & 0.2504 & 0.2460 & 0.3048 & 0.2888 & 0.2752 \\
\hline \multicolumn{6}{|l|}{ B. Monthly earnings } \\
\hline \multirow[t]{2}{*}{ Treatment group - ITT } & $332.23^{* * *}$ & $328.18^{* *}$ & 179.00 & 98.96 & $265.19^{* *}$ \\
\hline & {$[124.77]$} & {$[149.34]$} & {$[151.70]$} & {$[159.27]$} & {$[127.59]$} \\
\hline \multirow[t]{2}{*}{ Completed training - TOT } & $691.20^{* * *}$ & $664.43 * *$ & 362.41 & 200.35 & $536.91^{* *}$ \\
\hline & {$[243.32]$} & {$[300.55]$} & {$[307.27]$} & {$[322.60]$} & {$[257.31]$} \\
\hline Control group mean & 512.04 & 623.50 & 775.47 & 809.29 & 627.29 \\
\hline \multicolumn{6}{|l|}{ C. Credit in good standing } \\
\hline \multirow[t]{2}{*}{ Treatment group - ITT } & $0.0455^{* *}$ & $0.0674^{*}$ & 0.0247 & 0.0350 & 0.0360 \\
\hline & {$[0.0227]$} & {$[0.0348]$} & {$[0.0315]$} & {$[0.0358]$} & {$[0.0244]$} \\
\hline \multirow[t]{2}{*}{ Completed training - TOT } & $0.0937^{* *}$ & $0.1389^{*}$ & 0.0508 & 0.0722 & 0.0742 \\
\hline & {$[0.0469]$} & {$[0.0714]$} & {$[0.0646]$} & {$[0.0736]$} & {$[0.0501]$} \\
\hline Control group mean & 0.0882 & 0.1070 & 0.1326 & 0.1230 & 0.1084 \\
\hline \multicolumn{6}{|l|}{ D. Credit inquiries } \\
\hline \multirow[t]{2}{*}{ Treatment group - ITT } & $0.0776^{* *}$ & 0.0006 & -0.0212 & -0.0062 & 0.0327 \\
\hline & {$[0.0300]$} & {$[0.0663]$} & {$[0.0359]$} & {$[0.0797]$} & {$[0.0252]$} \\
\hline \multirow[t]{2}{*}{ Completed training - TOT } & $0.1582^{* * *}$ & 0.0012 & -0.0432 & -0.0126 & 0.0667 \\
\hline & {$[0.0601]$} & {$[0.1351]$} & {$[0.0734]$} & {$[0.1625]$} & {$[0.0509]$} \\
\hline Control group mean & 0.1881 & 0.2513 & 0.2877 & 0.3957 & 0.2333 \\
\hline Observations & 407 & 407 & 407 & 407 & 407 \\
\hline
\end{tabular}

Notes: the TOT coefficients correspond to instrumental variable regressions where the completed training indicator is instrumented by the treatment assignment variable. All regressions include controls for gender, year of birth dummies, children in the household, education level, and marital status. All regressions also include the average of the pre-treatment formal employment variable for the period Q1-2008 to Q3-2010. Panels B, C and D also include measures of pre-treatment earnings, credit in good standing and number of credit inquiries (quarterly), respectively. Robust standard errors in brackets. Sources: entra21, Sistema Integrado Previsional Argentino (SIPA), Administración Nacional de la Seguridad Social (ANSES), Banco Central de la República Argentina and EQUIFAX-VERAZ.

Robust standard errors in brackets. * significant at $10 \%$;* significant at $5 \%$; ** significant at $1 \%$. 
Table 3: Effects on formal employment. Heterogeneous impact

\begin{tabular}{|c|c|c|c|c|c|}
\hline & $\begin{array}{c}\text { Average } \\
\text { Q2-2011/Q3-2012 }\end{array}$ & Q3-2012 & $\begin{array}{c}\text { Average } \\
\text { Q4-2012/Q4-2013 }\end{array}$ & Q4-2013 & $\begin{array}{c}\text { Average } \\
\text { Q2-2011/Q4-2013 }\end{array}$ \\
\hline \multicolumn{6}{|l|}{ A. By gender } \\
\hline \multirow[t]{2}{*}{ Treatment group*Men } & $0.2392^{* * *}$ & $0.2793^{* * *}$ & $0.2258^{* * *}$ & $0.2450 * *$ & $0.2331^{* * *}$ \\
\hline & {$[0.0822]$} & {$[0.1010]$} & {$[0.0870]$} & {$[0.1026]$} & {$[0.0772]$} \\
\hline \multirow[t]{2}{*}{ Treatment group } & 0.0054 & 0.0154 & -0.0266 & -0.0378 & -0.0092 \\
\hline & {$[0.0411]$} & {$[0.0521]$} & {$[0.0456]$} & {$[0.0486]$} & {$[0.0396]$} \\
\hline \multirow[t]{2}{*}{ Men } & 0.0240 & 0.0182 & 0.0927 & 0.0756 & 0.0552 \\
\hline & {$[0.0601]$} & {$[0.0729]$} & {$[0.0665]$} & {$[0.0760]$} & {$[0.0576]$} \\
\hline Observations & 407 & 407 & 407 & 407 & 407 \\
\hline Control group mean & 0.2137 & 0.2177 & 0.2500 & 0.2500 & 0.2302 \\
\hline \multicolumn{6}{|l|}{ B. Age groups 18-24/25-30 } \\
\hline \multirow[t]{2}{*}{ Treatment group*Age 18-24 } & 0.0889 & 0.0973 & 0.1202 & 0.1026 & 0.1031 \\
\hline & {$[0.0709]$} & {$[0.0873]$} & {$[0.0792]$} & {$[0.0878]$} & {$[0.0689]$} \\
\hline \multirow[t]{2}{*}{ Treatment group } & 0.0299 & 0.0442 & -0.0183 & -0.0124 & 0.0080 \\
\hline & {$[0.0519]$} & {$[0.0629]$} & {$[0.0578]$} & {$[0.0632]$} & {$[0.0507]$} \\
\hline \multirow[t]{2}{*}{ Age 18-24 } & 0.0351 & -0.0091 & -0.0062 & -0.0318 & 0.0163 \\
\hline & {$[0.0547]$} & {$[0.0690]$} & {$[0.0621]$} & {$[0.0692]$} & {$[0.0539]$} \\
\hline Observations & 407 & 407 & 407 & 407 & 407 \\
\hline Control group mean & 0.1968 & 0.2169 & 0.2627 & 0.2410 & 0.2267 \\
\hline
\end{tabular}

Notes: Regression controls as in Table 2, with the exception of the regressions in panel B in which the year of birth categories were replaced with age range categories. Sources: entra21, Administración Nacional de la Seguridad Social (ANSES) and Sistema Integrado Previsional Argentino (SIPA).

Robust standard errors in brackets. ${ }^{*}$ significant at $10 \% ;{ }^{* *}$ significant at $5 \%$; ${ }^{* * *}$ significant at $1 \%$. 
Table 4: Program effects on monthly earnings. Heterogeneous impact and bounds

\begin{tabular}{|c|c|c|c|c|c|}
\hline & $\begin{array}{c}\text { Average } \\
\text { Q2-2011 to Q3-2012 }\end{array}$ & Q3-2012 & $\begin{array}{c}\text { Average } \\
\text { Q4-2012 to Q4-2013 }\end{array}$ & Q4-2013 & $\begin{array}{c}\text { Average } \\
\text { Q2-2011 to Q4-2013 }\end{array}$ \\
\hline \multicolumn{6}{|l|}{ A. By gender } \\
\hline Treatment group*Men & $\begin{array}{c}1,097.68^{* * *} \\
{[282.44]}\end{array}$ & $\begin{array}{c}1,325.70^{* * *} \\
{[343.45]}\end{array}$ & $\begin{array}{c}1,134.28 * * * \\
{[353.90]}\end{array}$ & $\begin{array}{l}929.31^{* *} \\
{[390.18]}\end{array}$ & $\begin{array}{c}1,113.69^{* * *} \\
{[288.97]}\end{array}$ \\
\hline Treatment group & $\begin{array}{c}12.99 \\
{[111.64]}\end{array}$ & $\begin{array}{c}-57.37 \\
{[139.18]}\end{array}$ & $\begin{array}{l}-150.88 \\
{[142.23]}\end{array}$ & $\begin{array}{l}-171.31 \\
{[149.59]}\end{array}$ & $\begin{array}{c}-58.70 \\
{[116.94]}\end{array}$ \\
\hline Men & $\begin{array}{c}-35.97 \\
{[157.79]}\end{array}$ & $\begin{array}{l}-54.84 \\
{[217.41]}\end{array}$ & $\begin{array}{c}199.69 \\
{[217.88]}\end{array}$ & $\begin{array}{c}250.10 \\
{[250.42]}\end{array}$ & $\begin{array}{c}67.13 \\
{[171.19]}\end{array}$ \\
\hline $\begin{array}{l}\text { Observations } \\
\text { Control group mean }\end{array}$ & $\begin{array}{c}407 \\
442.09 \\
\end{array}$ & $\begin{array}{c}407 \\
542.68 \\
\end{array}$ & $\begin{array}{c}407 \\
641.69 \\
\end{array}$ & $\begin{array}{c}407 \\
666.06 \\
\end{array}$ & $\begin{array}{c}407 \\
529.41 \\
\end{array}$ \\
\hline \multicolumn{6}{|l|}{ B. Age groups 18-24/25-30 } \\
\hline Treatment group*Age 18-24 & $\begin{array}{c}74.30 \\
{[221.55]}\end{array}$ & $\begin{array}{l}168.66 \\
{[268.71]}\end{array}$ & $\begin{array}{c}288.15 \\
{[267.75]}\end{array}$ & $\begin{array}{c}182.15 \\
{[287.23]}\end{array}$ & $\begin{array}{c}167.86 \\
{[226.94]}\end{array}$ \\
\hline Treatment group & $\begin{array}{l}296.22^{*} \\
{[175.49]}\end{array}$ & $\begin{array}{c}231.69 \\
{[201.76]}\end{array}$ & $\begin{array}{c}31.05 \\
{[205.43]}\end{array}$ & $\begin{array}{c}24.73 \\
{[209.11]}\end{array}$ & $\begin{array}{l}180.20 \\
{[174.73]}\end{array}$ \\
\hline Age 18-24 & $\begin{array}{l}-52.89 \\
{[152.14]}\end{array}$ & $\begin{array}{l}-101.52 \\
{[194.04]}\end{array}$ & $\begin{array}{c}11.16 \\
{[192.62]}\end{array}$ & $\begin{array}{c}66.17 \\
{[213.11]}\end{array}$ & $\begin{array}{l}-24.87 \\
{[160.20]}\end{array}$ \\
\hline $\begin{array}{l}\text { Observations } \\
\text { Control group mean }\end{array}$ & $\begin{array}{c}407 \\
428.43\end{array}$ & $\begin{array}{c}407 \\
562.40\end{array}$ & $\begin{array}{c}407 \\
649.33\end{array}$ & $\begin{array}{c}407 \\
600.05\end{array}$ & $\begin{array}{c}407 \\
525.07\end{array}$ \\
\hline Panel C. Bounds & & & & & \\
\hline Lower Bound (Only monotonicity) & -467.14 & $-1,084.30$ & -247.03 & -369.44 & -322.98 \\
\hline Lower Bound (Attanasio et al) & 506.16 & 219.85 & 427.14 & 265.00 & 457.97 \\
\hline Upper Bound & $1,479.46$ & $1,524.00$ & $1,101.30$ & 899.43 & $1,238.93$ \\
\hline
\end{tabular}

Notes: Regression controls as in Table 2, with the exception of the regressions in panel B in which the year of birth categories were replaced with age range categories. See Section 4 for details about the construction of earning bounds. Sources: entra21 and Sistema Integrado Previsional Argentino (SIPA).

Robust standard errors in brackets. ${ }^{*}$ significant at $10 \% ;{ }^{* *}$ significant at $5 \%$; ** significant at $1 \%$. 
Table 5: Program impact on employment aggregates over time: Ever formally employed, ever entered and ever left formal employment

\begin{tabular}{lccc}
\hline & Q2-2011/Q3-2012 & Q4-2012/Q4-2013 & Q2-2011/Q4-2013 \\
\hline A. Ever formally employed & & & \\
Treatment group & $0.1134^{* *}$ & $0.0793^{*}$ & $0.0983^{* *}$ \\
& {$[0.0487]$} & {$[0.0473]$} & {$[0.0471]$} \\
Control group mean & 0.4011 & 0.4011 & 0.5080 \\
\hline B. Ever entered formal employment & & & \\
Treatment group & 0.0422 & 0.0043 & 0.0239 \\
& {$[0.0466]$} & {$[0.0417]$} & {$[0.0487]$} \\
Control group mean & 0.2727 & 0.2193 & 0.4171 \\
\hline C. Ever left formal employment & & & 0.0332 \\
Treatment group & 0.0069 & 0.0483 & {$[0.0484]$} \\
& {$[0.0440]$} & {$[0.0409]$} & 0.3636 \\
Control group mean & 0.2567 & 0.1711 & 407 \\
\hline Observations & 407 & 407 & \\
\hline
\end{tabular}

Notes: Regression controls as in Table 2. Sources: entra21, Administración Nacional de la Seguridad Social (ANSES) and Sistema Integrado Previsional Argentino (SIPA).

Robust standard errors in brackets. ${ }^{*}$ significant at $10 \% ;{ }^{* *}$ significant at $5 \%$; ${ }^{* *}$ significant at $1 \%$. 
Table 6: Employment transitions (monthly data)

\begin{tabular}{|c|c|c|c|}
\hline & $\begin{array}{c}\text { Formal employment } \\
04-2011 / 09-2012\end{array}$ & $\begin{array}{c}\text { Formal employment } \\
10-2012 / 11-2013\end{array}$ & $\begin{array}{c}\text { Formal employment } \\
04-2011 / 11-2013\end{array}$ \\
\hline \multicolumn{4}{|l|}{ A. All sample } \\
\hline \multirow[t]{2}{*}{ Persistence } & $0.0346^{*}$ & -0.0165 & 0.0088 \\
\hline & {$[0.0183]$} & {$[0.0139]$} & {$[0.0129]$} \\
\hline \multirow[t]{2}{*}{ Access } & 0.0014 & 0.0079 & 0.0038 \\
\hline & {$[0.0062]$} & {$[0.0062]$} & {$[0.0049]$} \\
\hline \multirow[t]{2}{*}{ Dependence } & $0.8522^{* * *}$ & $0.9170 * * *$ & $0.8846^{* * *}$ \\
\hline & {$[0.0176]$} & {$[0.0118]$} & {$[0.0112]$} \\
\hline Observations & 7,326 & 5,698 & 13,024 \\
\hline \multicolumn{4}{|l|}{ B. Women only } \\
\hline \multirow[t]{2}{*}{ Persistence } & -0.0139 & $-0.0362^{*}$ & -0.0246 \\
\hline & {$[0.0216]$} & {$[0.0189]$} & {$[0.0162]$} \\
\hline \multirow[t]{2}{*}{ Access } & -0.0007 & 0.0074 & 0.0026 \\
\hline & {$[0.0061]$} & {$[0.0058]$} & {$[0.0047]$} \\
\hline \multirow[t]{2}{*}{ Dependence } & $0.8966^{* * *}$ & $0.9354^{* * *}$ & $0.9163^{* * *}$ \\
\hline & {$[0.0191]$} & {$[0.0127]$} & {$[0.0126]$} \\
\hline Observations & 5,022 & 3,906 & 8,928 \\
\hline \multicolumn{4}{|l|}{ C. Men only } \\
\hline \multirow[t]{2}{*}{ Persistence } & $0.0996^{* * *}$ & 0.0074 & $0.0522^{* *}$ \\
\hline & {$[0.0291]$} & {$[0.0219]$} & {$[0.0205]$} \\
\hline \multirow[t]{2}{*}{ Access } & 0.0172 & 0.0267 & 0.0192 \\
\hline & {$[0.0189]$} & {$[0.0201]$} & {$[0.0156]$} \\
\hline \multirow[t]{2}{*}{ Dependence } & $0.7690 * * *$ & $0.8771^{* * *}$ & $0.8251^{* * *}$ \\
\hline & {$[0.0298]$} & {$[0.0232]$} & {$[0.0193]$} \\
\hline Observations & 2,304 & 1,792 & 4,096 \\
\hline \multicolumn{4}{|l|}{ D. Age group 18-24 } \\
\hline \multirow[t]{2}{*}{ Persistence } & $0.0560 * *$ & -0.0029 & 0.0263 \\
\hline & {$[0.0246]$} & {$[0.0172]$} & {$[0.0167]$} \\
\hline \multirow[t]{2}{*}{ Access } & 0.0042 & 0.0107 & 0.0069 \\
\hline & {$[0.0096]$} & {$[0.0094]$} & {$[0.0075]$} \\
\hline \multirow[t]{2}{*}{ Dependence } & $0.8302^{* * *}$ & $0.9045^{* * *}$ & $0.8675 * * *$ \\
\hline & {$[0.0239]$} & {$[0.0168]$} & {$[0.0149]$} \\
\hline Observations & 4,158 & 3,234 & 7,392 \\
\hline \multicolumn{4}{|l|}{ E. Age group 25-30 } \\
\hline \multirow[t]{2}{*}{ Persistence } & -0.0024 & -0.0377 & -0.0202 \\
\hline & {$[0.0254]$} & {$[0.0264]$} & {$[0.0214]$} \\
\hline \multirow[t]{2}{*}{ Access } & -0.0011 & 0.0007 & -0.0008 \\
\hline & {$[0.0080]$} & {$[0.0081]$} & {$[0.0064]$} \\
\hline \multirow[t]{2}{*}{ Dependence } & $0.8856^{* * *}$ & $0.9268 * * *$ & $0.9076^{* * *}$ \\
\hline & {$[0.0237]$} & {$[0.0172]$} & {$[0.0165]$} \\
\hline Observations & 3,168 & 2,464 & 5,632 \\
\hline
\end{tabular}

Notes: Regression controls as in Table 2. Sources: entra21 and Sistema Integrado Previsional Argentino (SIPA). Standard errors clustered by individuals in brackets. ${ }^{*}$ significant at $10 \%$; ${ }^{*}$ significant at $5 \%$; $* *$ significant at $1 \%$. 
Table 7: Probability of staying with the same employer year on year

\begin{tabular}{lccc}
\hline & Same employer & Same employer & Same employer \\
& Q3-2010\&Q3-2011 & Q4-2011\&Q4-2012 & Q4-2011\&Q4-2013 \\
\hline A. All sample & & & \\
Treatment group & -0.0123 & 0.0505 & 0.0479 \\
Observations & {$[0.0124]$} & {$[0.0346]$} & {$[0.0294]$} \\
Control group mean & 407 & 407 & 407 \\
\hline B. By gender & 0.0214 & 0.1176 & 0.0749 \\
Treatment group*Men & & & \\
& -0.0086 & $0.1608^{* *}$ & 0.0433 \\
Treatment group & {$[0.0304]$} & {$[0.0813]$} & {$[0.0699]$} \\
& -0.0099 & -0.0085 & 0.0291 \\
Men & {$[0.0127]$} & {$[0.0395]$} & {$[0.0338]$} \\
Observations & 0.0149 & -0.0463 & -0.0050 \\
Control group mean & {$[0.0232]$} & {$[0.0565]$} & {$[0.0458]$} \\
\hline C. Age groups 18-24/25-30 & 407 & 407 & 407 \\
Treatment group*Age 18-24 & 0.0161 & 0.1210 & 0.0726 \\
Treatment group & -0.0025 & & 0.0587 \\
Age 18-24 & {$[0.0237]$} & {$[0.0676]$} & {$[0.0587]$} \\
Observations & -0.0133 & -0.0254 & 0.0129 \\
Control group mean & {$[0.0131]$} & {$[0.0439]$} & {$[0.0405]$} \\
\hline
\end{tabular}

Notes: Regression controls as in Table 2. Sources: entra21 and Sistema Integrado Previsional Argentino (SIPA). Robust standard errors in brackets. * significant at $10 \%$; ** significant at $5 \%$; *** significant at $1 \%$. 
Table 8: Program effects on welfare programs participation (AUH), Q2-2011 to Q4-2013. Women only

\begin{tabular}{lccc}
\hline & Always AUH & Always AUH & Always AUH \\
& Q2-2011/Q3-2012 & Q4-2012/Q4-2013 & Q2-2011/Q4-2013 \\
\hline A. Women only & & & \\
Treatment group & -0.0080 & 0.0015 & 0.0077 \\
& {$[0.0312]$} & {$[0.0393]$} & {$[0.0315]$} \\
Observations & 279 & 279 & 279 \\
Control group mean & 0.1290 & 0.1694 & 0.1048 \\
\hline B. Women by age groups & & & \\
Treatment group*Age 18-24 & -0.0663 & -0.0706 & $-0.1147^{*}$ \\
& {$[0.0696]$} & {$[0.0837]$} & {$[0.0692]$} \\
Random assignment & 0.0286 & 0.0417 & 0.0674 \\
& {$[0.0635]$} & {$[0.0678]$} & {$[0.0626]$} \\
Age 18-24 & 0.0025 & 0.0419 & 0.0207 \\
Observations & {$[0.0528]$} & {$[0.0638]$} & {$[0.0532]$} \\
Control group mean & 279 & 279 & 279 \\
\hline
\end{tabular}

Notes: Regression controls as in Table 2, with the exception of the regressions in panel B in which the year of birth categories were replaced with age range categories. Sources: entra21 and Administración Nacional de la Seguridad Social (ANSES).

Robust standard errors in brackets. ${ }^{*}$ significant at $10 \% ;{ }^{* *}$ significant at $5 \%$; *** significant at $1 \%$. 
Table 9: Program effects on consumer credit use, Q2-2011 to Q4-2013 ITT (OLS). Heterogeneous impact

\begin{tabular}{|c|c|c|c|c|c|c|}
\hline & \multicolumn{3}{|c|}{ Credit in good standing } & \multicolumn{3}{|c|}{ Number of credit inquiries } \\
\hline & $\begin{array}{c}\text { Average } \\
\text { Q2-11/Q3-12 }\end{array}$ & $\begin{array}{c}\text { Average } \\
\text { Q4-12/Q4-13 }\end{array}$ & $\begin{array}{c}\text { Average } \\
\text { Q2-11/Q4-13 }\end{array}$ & $\begin{array}{c}\text { Average } \\
\text { Q2-11/Q3-12 }\end{array}$ & $\begin{array}{c}\text { Average } \\
\text { Q4-12-Q4-13 }\end{array}$ & $\begin{array}{c}\text { Average } \\
\text { Q2-11-Q4-13 }\end{array}$ \\
\hline \multicolumn{7}{|l|}{ A. All sample } \\
\hline \multirow[t]{2}{*}{ Treatment group } & $0.0455^{* *}$ & 0.0247 & 0.0360 & $0.0776^{* *}$ & -0.0212 & 0.0327 \\
\hline & {$[0.0227]$} & {$[0.0315]$} & {$[0.0244]$} & {$[0.0300]$} & {$[0.0359]$} & {$[0.0252]$} \\
\hline Observations & 407 & 407 & 407 & 407 & 407 & 407 \\
\hline Control group mean & 0.0882 & 0.1326 & 0.1084 & 0.1881 & 0.2877 & 0.2333 \\
\hline \multicolumn{7}{|l|}{ A. By gender } \\
\hline \multirow[t]{2}{*}{ Treatment group*Men } & $0.1373^{* * *}$ & $0.1629^{* *}$ & $0.1489^{* * *}$ & $0.1991^{* * *}$ & $0.1640^{*}$ & $0.1832^{* * *}$ \\
\hline & {$[0.0530]$} & {$[0.0696]$} & {$[0.0560]$} & {$[0.0670]$} & {$[0.0837]$} & {$[0.0553]$} \\
\hline \multirow[t]{2}{*}{ Treatment group } & 0.0030 & -0.0258 & -0.0101 & 0.0152 & $-0.0725^{*}$ & -0.0247 \\
\hline & {$[0.0249]$} & {$[0.0357]$} & {$[0.0272]$} & {$[0.0343]$} & {$[0.0434]$} & {$[0.0307]$} \\
\hline \multirow[t]{2}{*}{ Men } & -0.0380 & $-0.0813^{*}$ & -0.0577 & $-0.0889^{* *}$ & -0.0744 & $-0.0823^{*}$ \\
\hline & {$[0.0325]$} & {$[0.0480]$} & {$[0.0362]$} & {$[0.0370]$} & {$[0.0701]$} & {$[0.0426]$} \\
\hline Observations & 407 & 407 & 407 & 407 & 407 & 407 \\
\hline Control group mean & 0.0968 & 0.1452 & 0.1188 & 0.2151 & 0.3065 & 0.2566 \\
\hline \multicolumn{7}{|l|}{ B. Age groups 18-24/25-30 } \\
\hline \multirow[t]{2}{*}{ Treatment group*Age 18-24 } & $0.0818^{*}$ & 0.0855 & $0.0834^{*}$ & $0.1107^{*}$ & $0.1797^{* *}$ & $0.1421^{* * *}$ \\
\hline & {$[0.0456]$} & {$[0.0624]$} & {$[0.0485]$} & {$[0.0590]$} & {$[0.0840]$} & {$[0.0546]$} \\
\hline \multirow[t]{2}{*}{ Treatment group } & -0.0009 & -0.0206 & -0.0098 & 0.0149 & $-0.1254^{* *}$ & -0.0489 \\
\hline & {$[0.0366]$} & {$[0.0457]$} & {$[0.0376]$} & {$[0.0407]$} & {$[0.0617]$} & {$[0.0391]$} \\
\hline \multirow[t]{2}{*}{ Age 18-24 } & $-0.0536^{*}$ & -0.0393 & -0.0471 & 0.0231 & -0.1121 & -0.0384 \\
\hline & {$[0.0323]$} & {$[0.0480]$} & {$[0.0357]$} & {$[0.0426]$} & {$[0.0702]$} & {$[0.0457]$} \\
\hline Observations & 407 & 407 & 407 & 407 & 407 & 407 \\
\hline Control group mean & 0.1205 & 0.1470 & 0.1325 & 0.1847 & 0.3590 & 0.2640 \\
\hline
\end{tabular}

Notes: Regression controls as in Table 2, with the exception of the regressions in panel B in which the year of birth categories were replaced with age range categories. Sources: entra21 and EQUIFAX-VERAZ.

Robust standard errors in brackets. ${ }^{*}$ significant at $10 \%$; ** significant at $5 \%$; *** significant at $1 \%$. 
Figure 1: Evolution of formal employment, labor earnings and consumer credit in good standing

A. Formal employment by group, quarterly

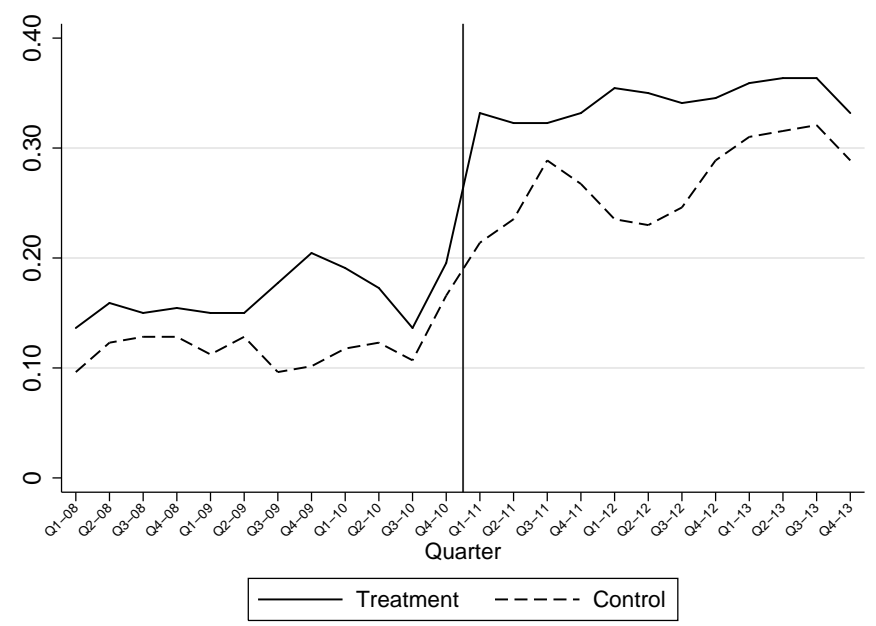

B. Average real labor earnings by group, quarterly

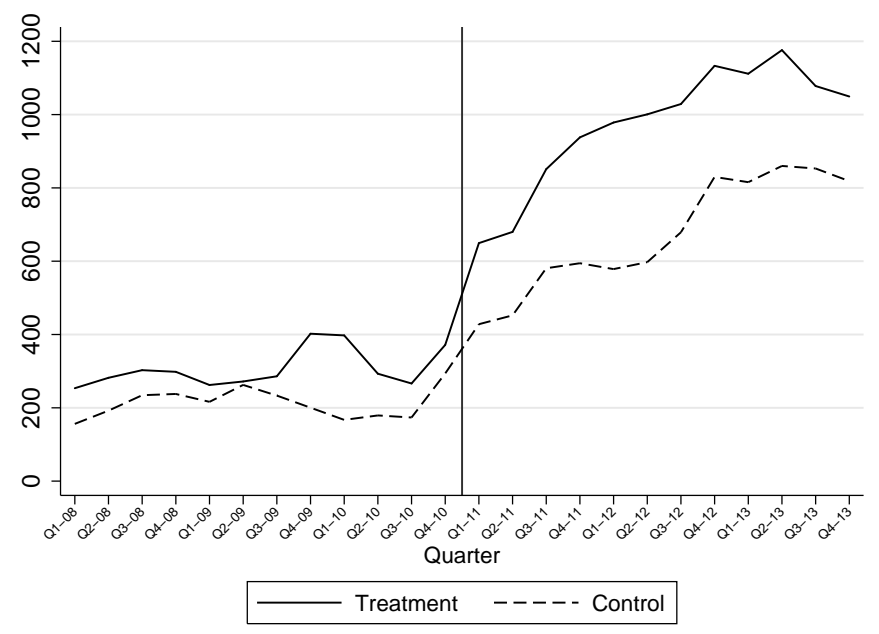

C. Consumer credit in good standing by group, quarterly

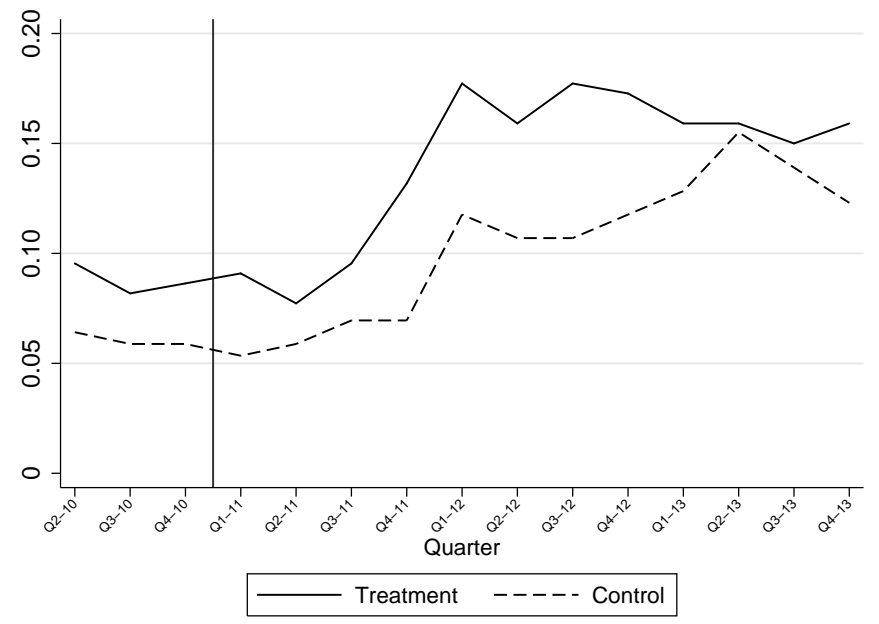

Notes: Vertical line indicates when the program took place. Sources: entra21, Sistema Integrado Previsional Argentino (SIPA) and Banco Central de la República Argentina. 